\title{
Pricing Immigration
}

\author{
Simon Hix, Eric Kaufmann, Thomas J. Leeper
}

February 2, 2020

\begin{abstract}
Immigration is highly salient for voters in Europe and the United States and has generated considerable academic debate about the causes of preferences over immigration. This debate centers around the relative influences of sociotropic or personal economic considerations, as well as non-economic threats. We provide a test of the competing egocentric, sociotropic, and non-economic paradigms using a novel constrained preference experiment in which respondents are asked to trade-off preferred reductions in immigration levels with realistic estimates of the personal or societal costs associated with those reductions. This survey experiment, performed on a national sample of British YouGov panelists, allows us to measure the price-elasticity of the public's preferences with regard to levels of European and non-European immigration. Respondents were willing to admit more immigrants when restriction carries economic costs, with egocentric considerations as important as sociotropic ones. People who voted for the UK to Leave the European Union in the 2016 referendum are less price-elastic than those voting Remain, indicating that non-economic concerns are also important.
\end{abstract}


Are people who prefer lower immigration levels sensitive to the economic costs of reducing immigration? This question is particularly relevant in Britain in light of ongoing debate over Britain's exit from the European Union. Immigration has become increasingly salient since 2013 in many European countries and in the United States and has ranked among the top three issues for voters since 2002 (Duffy and Frere-Smith 2014), making it a uniquely persistent topic of political importance. We examine the connection between preferred immigration reductions and their economic costs through a novel constrainedpreference survey experiment that adds to the scholarly understanding of immigration preferences in several important ways. We find economic considerations may matter more than generally thought as inhibitors of restrictionist policy preferences, and that egocentric economic motives can be as important as sociotropic ones in shaping these preferences.

Previous analyses of immigration attitudes support cultural threat and sociotropic economic explanations - those regarding the economy as a whole - over egocentric material interests such as threats to one's own standing in the labor market (Hainmueller and Hiscox 2010). On the cultural side, living near refugee processing centres or inhabiting ethnically-changing neighbourhoods or countries tends to lead to more negative attitudes to immigrants and a preference for lower levels of immigration (Newman 2013; Lubbers 2006; Enos 2014). Brader, Valentino, and Suhay (2008) show, by manipulating the skin tone and ethnicity of an immigrant, that white Americans prefer European to non-European immigrants.

Sociotropic economic considerations are also seen as important. When asked about the reasons why they oppose immigration, many respondents cite competition for jobs or pressure on public services (Sides and Citrin 2007). Studies repeatedly find that respondents favor high-skilled over low-skilled immigrants (Bansak, Hainmueller, and Hangartner 2016). Panel studies, however, find no evidence that the economic cycle affects immigration opinion, but do find that changes in the stock of immigrants predicts opposition over time (Hatton 2016).

Deploying an innovative methodology designed to assess implicit cost constraints on immigration attitudes, we test the competing sociotropic or egocentric economic paradigms, as well as the role of non-economic motivations. We use a novel constrainedpreference experiment conducted on a national sample of UK adults to investigate the public's preferences over levels of European and non-European immigration. Rather than correlate economic considerations with immigration preferences in the unconstrained manner typical of most existing research, we force respondents to make a trade-off between lowering immigration and foregoing economic benefits. This approach reflects the observation by Kuklinski et al. $(2001,414)$ that "to the extent that citizens can express trade-offs explicitly and realistically, they will give policymakers informative signals about their priorities." Trade-offs, beyond measures of stated favorability or opposition toward 
immigration, more accurately reflect what citizens might want in realistic policy terms.

\section{Attitudes toward Immigration}

In light of the United Kingdom's 2016 vote to leave the European Union, polling finds that British citizens want both reduced immigration and improved economic growth. Opposition to immigration is particularly striking among "Leave" voters (Clarke, Goodwin, and Whiteley 2017) and polling indicates that nearly half (45\%) of British citizens would be unsatisfied with a Brexit outcome that continued to allow freedom of movement for EU citizens in order to retain Single Market access. ${ }^{1}$

Despite the prevalence of these restrictionist attitudes, there remain open questions about the degree to which an apparently unconditional opposition to migration may be affected by the economic costs that actually come with attenuating immigration levels. Indeed, it would appear that many British citizens favor reducing immigration and retaining access to the Single Market ( $43 \%$ believe the EU should offer a free trade deal without guaranteeing freedom of movement $)^{2}$ despite this combination of policies being highly unlikely to emerge from the Brexit negotiations. This "cake and eat it" set of preferences highlights a limitation of traditional survey research, which permits citizens to express separate attitudes on what are ultimately inseparable preferences (Lacy 2001).

We ask: are citizens willing to pay a (personal or societal) cost in order to defend a largely symbolic attitude such as opposition to immigration? The LSE's Centre for Economic Performance suggests, citing data from Boubtane, Dumont, and Rault (2015), that "cutting EU immigrants to 80,000 per year [half of current levels] is likely to shave $0.16 \%$ off productivity growth (Wadsworth et al. 2016). So about a decade after Brexit, UK GDP per capita will be about $1.6 \%$ lower than it would have otherwise been." By those numbers, cutting EU immigration entirely would lower GDP per capita by more than $3 \%$ by 2030 . Opposition to immigration necessarily means an economic cost, even if citizens do not know it. One study suggests that approximately $35 \%$ of Leave voters would be willing to pay $5 \%$ of their personal income to reduce EU immigration to zero, but 6 in 10 voters are unwilling to sacrifice any income to reduce immigration Kaufmann (2017). This research tested whether egocentric economic considerations affect views on EU immigration but did not ask how respondents might trade off between immigration levels and sociotropic economic costs, nor did it ask about non-EU immigration. We do just this, comparing egocentric and sociotropic economic concerns, as well as preferred EU and non-EU immigration levels.

\footnotetext{
${ }^{1}$ http://www . comresglobal.com/polls/bbc-news-brexit-expectations-poll/

${ }^{2}$ YouGov. 2016. "European voters reject 'generous deal' with UK post-Brexit". https://yougov. co.uk/news/2016/07/08/european-voters-reject-generous-deal/.
} 


\section{Theory and Expectations}

Our goal is to know what the public's preferred level of net EU and non-EU immigration to the UK is, and what economic costs individuals are willing to pay to achieve that. Our expectations are straightforward. We are interested in two types of economic costs: egocentric (personal costs) and sociotropic (costs to society as a whole) and two types of immigration (EU and non-EU). Thus we expect:

H1: The imposition of a sociotropic cost in terms of foregone national Gross Domestic Product (GDP) will make citizens more favorable toward higher levels of immigration (i.e., immigration levels closer to the status quo).

H2: The imposition of an egocentric cost on personal income will make citizens more favorable toward higher levels of immigration (i.e., immigration levels closer to the status quo).

H3: Raising sociotropic (H3a) or egocentric (H3b) costs from a low cost to high cost will further increase favorability toward higher levels of immigration.

Thus we anticipate that shifting the cost of achieving zero-net immigration from $5 \%$ of GDP to $10 \%$ of GDP should further increase favorability toward immigration. Given that the literature suggests sociotropic costs matter more for immigration opinion than egocentric costs, we further expect that:

H4: Sociotropic costs in terms of foregone GDP will have a larger effect than the egocentric cost of lost household income in convincing respondents to accept higher levels immigration.

\section{Design and Methods}

To measure preferences toward immigration when constrained by cost, we rely on a survey experiment that presents this trade-off graphically and allows respondents to express their desired reduction in net immigration (between no reduction and $100 \%$ reduction), constrained by an associated economic cost. We benchmark these constrained preferences using a within-subjects design that first measures individuals' unconstrained preferences for levels of EU and non-EU immigration.

The design then involves two subsequent manipulations. First, we randomly assign individuals to either an egocentric condition where economic costs are expressed in terms 
Table 1: Experimental Design and Sample Sizes

\begin{tabular}{lll}
\hline & Egocentric & Sociotropic \\
\hline High Cost & $1(\mathrm{n}=897)$ & $2(903)$ \\
Low Cost & $3(914)$ & $4(922)$ \\
\hline
\end{tabular}

of $\%$ of personal income or a sociotropic condition where costs are in terms of GDP per capita. This provides within-subjects tests of $\mathrm{H} 1$ and $\mathrm{H} 2$ (comparing constrained preferences to unconstrained preferences). Second, we test H3 by further randomizing individuals to either a "high cost" or "low cost" tradeoff curve, which adjusts the absolute cost associated with various reduced levels of immigration. The high cost condition imposes a 10\% cost (of GDP or personal income) for bringing net immigration to zero; the low cost condition imposes a $5 \%$ cost.

We test H3 and H4 through a 2x2 factorial design (4 conditions total; see Table 1). We repeat the experiment separately for EU and non-EU immigration, with the order of $\mathrm{EU} /$ non-EU immigration questions randomized.

We also ask a manipulation check to assess respondents' acceptance of the cost tradeoff: "Do you believe the economic costs of reducing immigration that you just read are just about right, or do you think reducing immigration will be much more costly or much less costly?" with a five-point scale from "Much more costly" to "Much less costly", or "Don't know".

Finally, we also included a separate two-condition experiment measuring preferences for a relative balance of EU and non-EU immigrants, where the manipulation entailed the inclusion or exclusion of an explicit statement of current relative levels ("Currently $37 \%$ of all immigrants to the UK are from the EU and the rest are from Asia, Africa, the Middle East, and the rest of the world.").

Our main outcome measure is simply respondents' preferred immigration levels, $\sum_{i=1}^{n} \frac{L_{i}}{n}$, where $L_{i}$ is the preferred level of immigration for respondent $i$, among $n$ total respondents. Because our design only allows respondents to express preferences for lower levels of net immigration (from 0 fewer immigrants to 165,000 fewer bringing total net immigration to zero), we can also state these preferred levels as preferred reductions, such that $R_{i}=165000-L_{i}$ for each respondent, separately for EU and non-EU immigration.

The causal effects of interest are the differences in preferred immigration levels across the various cost counterfactuals, such as the high sociotropic cost and low sociotropic cost conditions:

$$
\sum_{i=1}^{n_{1}} \frac{L_{i, \text { High Sociotropic }}}{n_{\text {High Sociotropic }}}-\sum_{j=1}^{n_{0}} \frac{L_{j, \text { Low Sociotropic }}}{n_{\text {Low Sociotropic }}}
$$

separately for EU and non-EU immigration. We can estimate this effect as a difference- 
in-differences of within-subject changes between unconstrained $(t=0)$ and constrained $(t=1)$ preference measures between experimental conditions:

$$
\sum_{i=1}^{n} \frac{L_{i, \text { Low Egocentric }, t=1}-L_{i, \text { Unconstrained }, t=0}}{n_{\text {Low Egocentric }}}-\sum_{j=1}^{n} \frac{L_{j, \text { Low Sociotropic }, t=1}-L_{j, \text { Unconstrained }, t=0}}{n_{\text {Low Sociotropic }}}
$$

The within-subject differences provide for tests of $H 1$ and $H 2$, and these differences-indifferences provide for tests of $H 3$ and $H 4$. We estimate effects for the high personal cost, high sociotropic cost, and low personal cost against the low sociotropic cost condition as a baseline, using OLS regression:

Difference $=\beta_{0}+\beta_{1}$ Low Egocentric $+\beta_{2}$ High Sociotropic $+\beta_{3}$ High Egocentric

The intercept, $\beta_{0}$, is an estimate of the impact of low sociotropic costs on preferred levels of immigration - a positive value would be consistent with $H 1$ such that respondents display preferences for higher levels of immigration when reductions are costly. ${ }^{3} \beta_{1}$ estimates Equation 2. To the extent that $\beta_{1}, \beta_{2}$, and $\beta_{3}$ are statistically distinguishable from zero, costs induce preferences for lower (if negative) or higher (if positive) levels of immigration than the low sociotropic cost. ${ }^{4}$

Most of our analysis focuses on preferred levels of EU and non-EU immigration and overall (summing preferences for both types). We further describe differences in preferences among Leave and Remain voters and voters of different socioeconomic classes. Though not causally intepretable, we expect respondents will accept a higher level of EU than non-EU immigration and, given that Leave voting in the 2016 referendum on EU membership appears more linked to authoritarianism and conservatism than economic concerns (Kaufmann 2017), we anticipate Leave voters should be more reluctant than Remain voters to relax their immigration preferences in the face of costs.

\section{Data Collection}

Data were gathered by YouGov through two separate waves of their online "Omnibus" panel (26 April and 2 May, 2017, ten months after the Brexit vote). The Omnibus panel is a non-probability panel of respondents who complete surveys in exchange for reward points. From this panel, respondents are selected using quota methods to reflect the composition of the UK population with respect to age, sex, education, and region.

\footnotetext{
${ }^{3}$ One could, alternatively, think of this effect as a positive value implying a preference for a smaller reduction in immigration levels when reductions are costly.

${ }^{4}$ Positive coefficients mean costs lead to preferences for smaller reductions compared to present levels and negative coefficients would mean costs lead to preferences for larger reductions compared to present levels.
} 


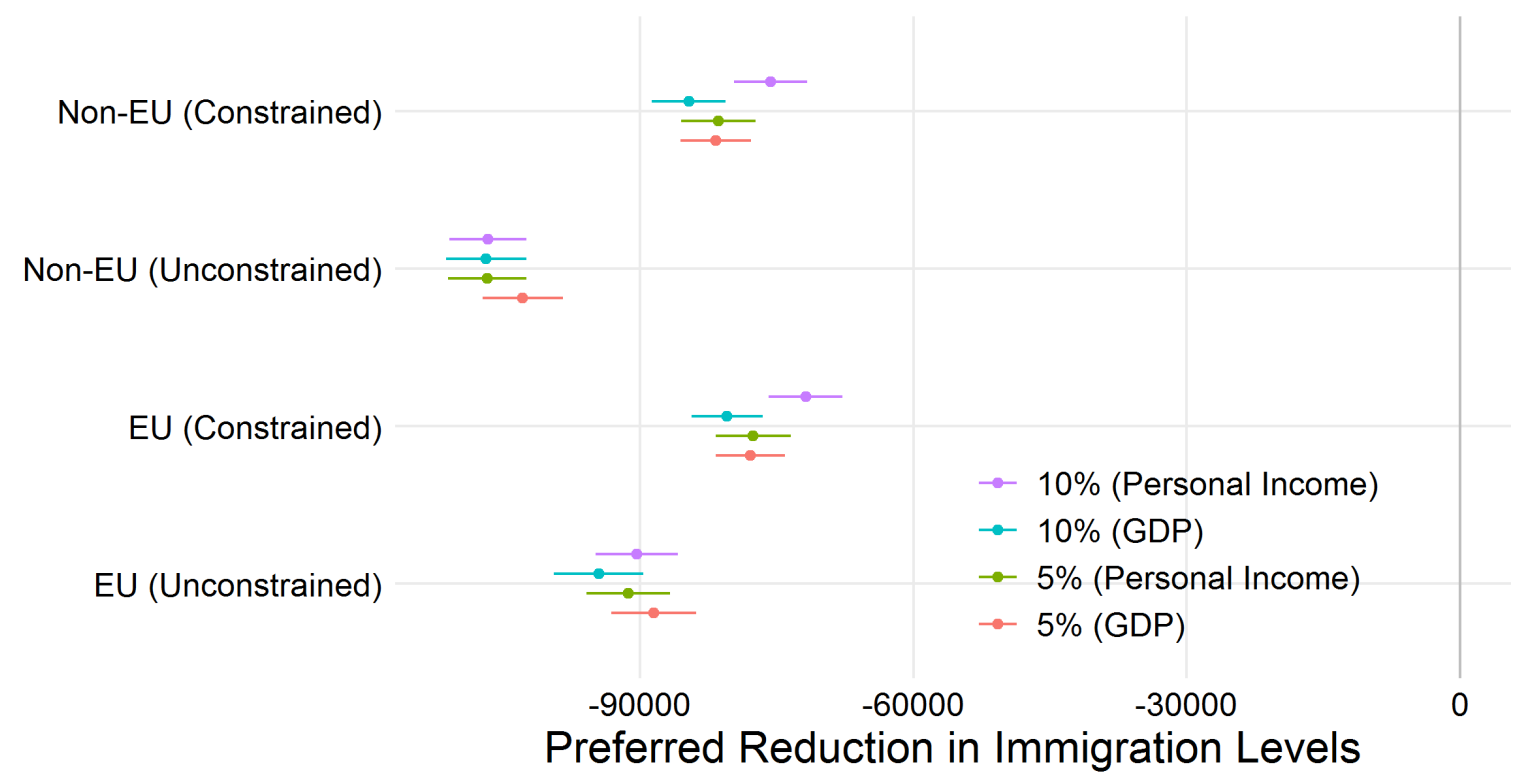

Figure 1: Preferred Reductions in EU and non-EU Immigration, Unconstrained or Constrained by Egocentric or Sociotropic Costs

Given the panel, we are able to rely on profile measures of respondents' characteristics: age, gender, social class, education, region, party identification, vote history (general election and EU membership referendum). $n=3,636$ respondents completed the survey and analyses are weighted according to poststratification weights (targetting UK census demographics) provided by YouGov.

\section{Results}

Respondents are in favor of substantial reductions in net immigration. Against the current 330,000 net annual immigrants - 165,000 net migrants from both the EU and outside the $\mathrm{EU}$ - the preferred reductions in immigration are substantial. On average, respondents prefer a reduction in EU immigration from 165,000 to 73,775 per year, a drop of 91,325 $(\mathrm{SE}=1201)$ and a reduction in non-EU immigration from 165,000 to 59,689, a drop of $105,311(\mathrm{SE}=1115)$. This adds up to preferring a level of net annual immigration of around 133,000, equal to about $40 \%$ of current levels. Figure 1 reports these reductions in EU and non-EU immigration levels under unconstrained and constrained conditions. The unconstrained conditions show the preference for lower levels of both non-EU and EU immigration. ${ }^{5}$

\footnotetext{
${ }^{5}$ We also attempted to directly measure respondents' preferred balance of EU and non-EU immigration using a separate experimental measure described in the previous section. Respondents preferred $53 \%$ non-EU to $47 \%$ EU immigration. This pattern did not respond to an experimental treatment providing accurate information on the current balance. Thus respondents directly report preferences for substantially lower non-EU immigration than EU immigration, but their preferences diverge from this pattern when asked to think in terms of relative shares.
} 
Table 2: Treatment Effects, Full Sample

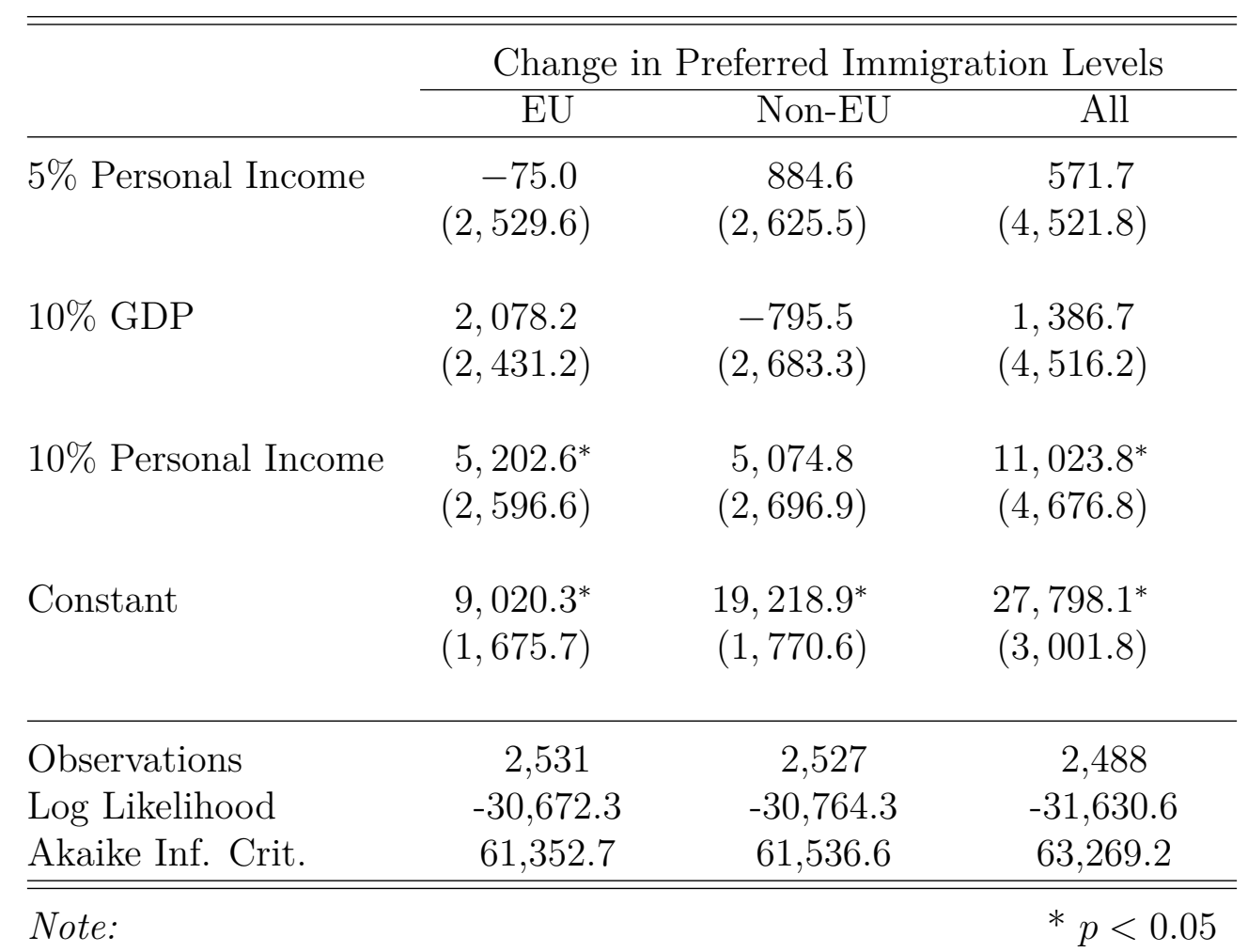

These are estimates of Equation 3, separately for EU (column 1) and Non-EU (column 2 ) immigration, and a pooled estimate (column 3). The outcome is a within-subject shift in preferred immigration levels (cost-constrained preference - unconstrained preference). The positive constant in each case indicates that the imposition of a low sociotropic costs increases preferred immigration levels. The remaining coefficients are differencesin-differences against that baseline condition (as in Equation 2). 
The constrained conditions in Figure 1 show how individuals' preferences change in the face of low or high personal or sociotropic costs. Table 2 reports estimates of these differences-in-differences. In the low-cost, societal condition (represented by the constant term in these specifications), respondents respond by accepting 9,000 more EU immigrants and 20,000 more non-EU immigrants per year. This result is strongly consistent with our expectation that sociotropic costs will shift preferences in favor of higher immigration levels $(H 1)$. Keeping in mind that respondents initially preferred higher reductions in non-EU than EU immigration, the larger effect of low societal costs for non-EU than EU immigrants (the constants in columns 1 and 2 of Table 2) mean that costs equalize preferences for levels of EU and non-EU immigration.

Asking respondents to consider a personal rather than sociotropic cost yields similar effects, consistent with $H 2$. The difference-in-differences between the low societal cost and low personal cost conditions (the first row of coefficients in Table 2) are not statistically distinguishable from zero, indicating that sociotropic and personal costs have similar effects on preferred immigration levels.

We expected higher costs would magnify these effects $(H 3)$, yet the differences-indifferences for the high cost conditions do not paint a consistent story. Increasing costs from $5 \%$ to $10 \%$ of GDP does not lead to significantly larger increases in preferred levels than the sociotropic cost condition (disconfirming H3a). ${ }^{6}$ Yet, higher personal costs do yield a significantly larger shift (consistent with $H 3 b$ ) for EU immigration levels. ${ }^{7}$

One possibility, of course, is that the egocentric costs manipulations were simply more evocative than the sociotropic, rather than an inherently meaningful difference in the influence of these two types of costs. Evaluating these results as a whole in light of the literature, which strongly expects sociotropic costs to be more consequential than egocentric costs in moving immigration preferences, we see no clear evidence for this (disconfirming H4). It is also possible respondents were unwilling to believe the cost estimates we provided. On our manipulation check, many respondents indicated they did not know the costs of immigration reductions; among those who provided a substantive answer, there was little variation across conditions in shares of respondents believing the costs were higher or lower than we implied. While respondents were somewhat more skeptical about the $10 \%$ personal income cost than the other stimuli, substantial proportions of respondents in every condition thought the costs we reported were "just about right" and majorities thought costs were even higher than we estimated so we are reasonably certain most respondents "took" the treatments at face value.

Whose preferences are shifting? Figure 2 provides a visual summary of the individuallevel relationship between unconstrained preferences (x-axis) and cost-constrained pref-

\footnotetext{
${ }^{6}$ Though the estimated coefficient is positive for EU immigration, it does not reach conventional levels of statistical significance; the effect for non-EU immigration is the opposite of what is expected by $H 3 a$.

${ }^{7}$ The estimate for Non-EU immigration is also positively signed but with a $t$-statistic of 1.88 .
} 


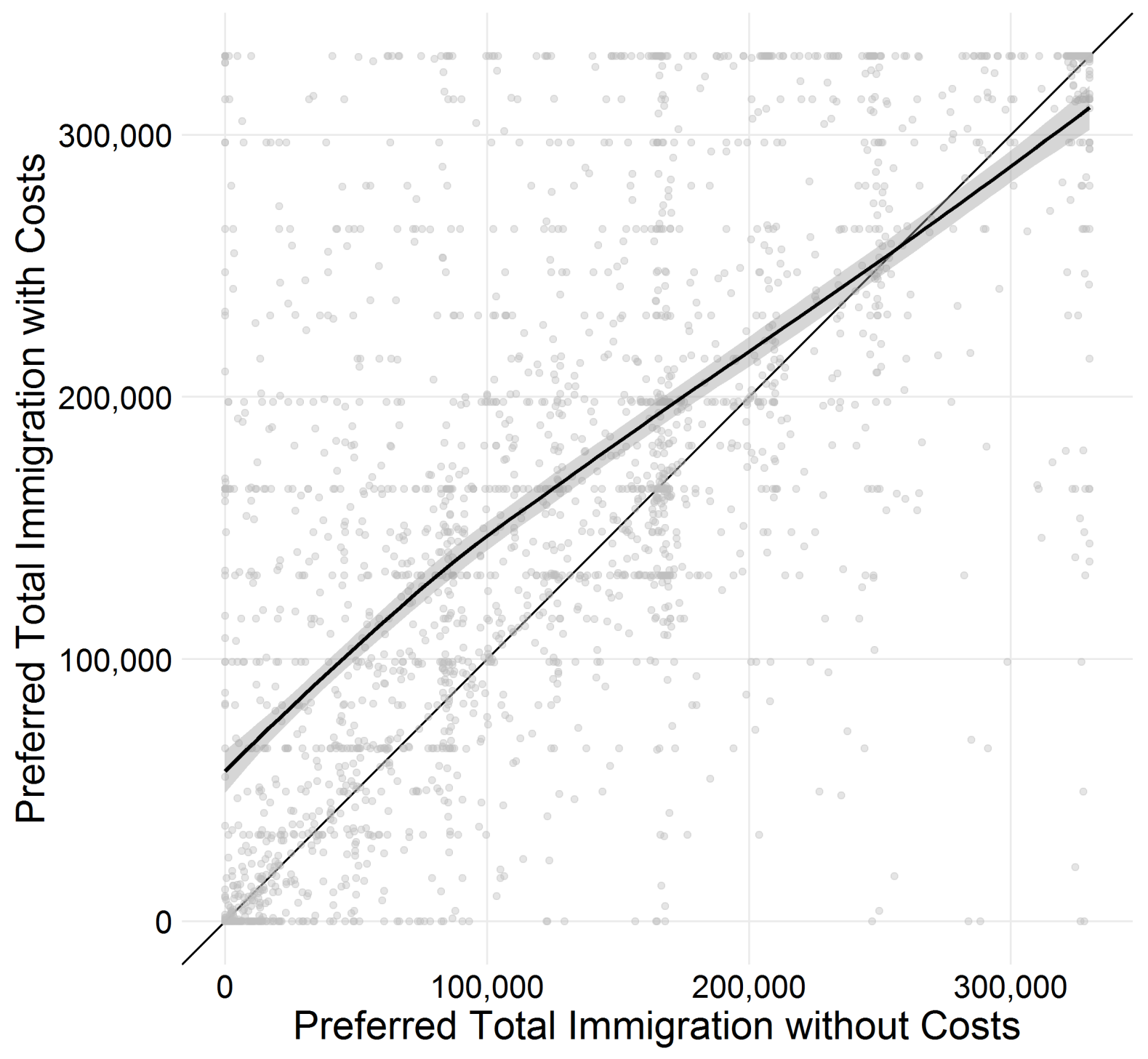

Figure 2: Preferred Constrained and Unconstrained Levels of Immigration, EU and nonEU Combined 

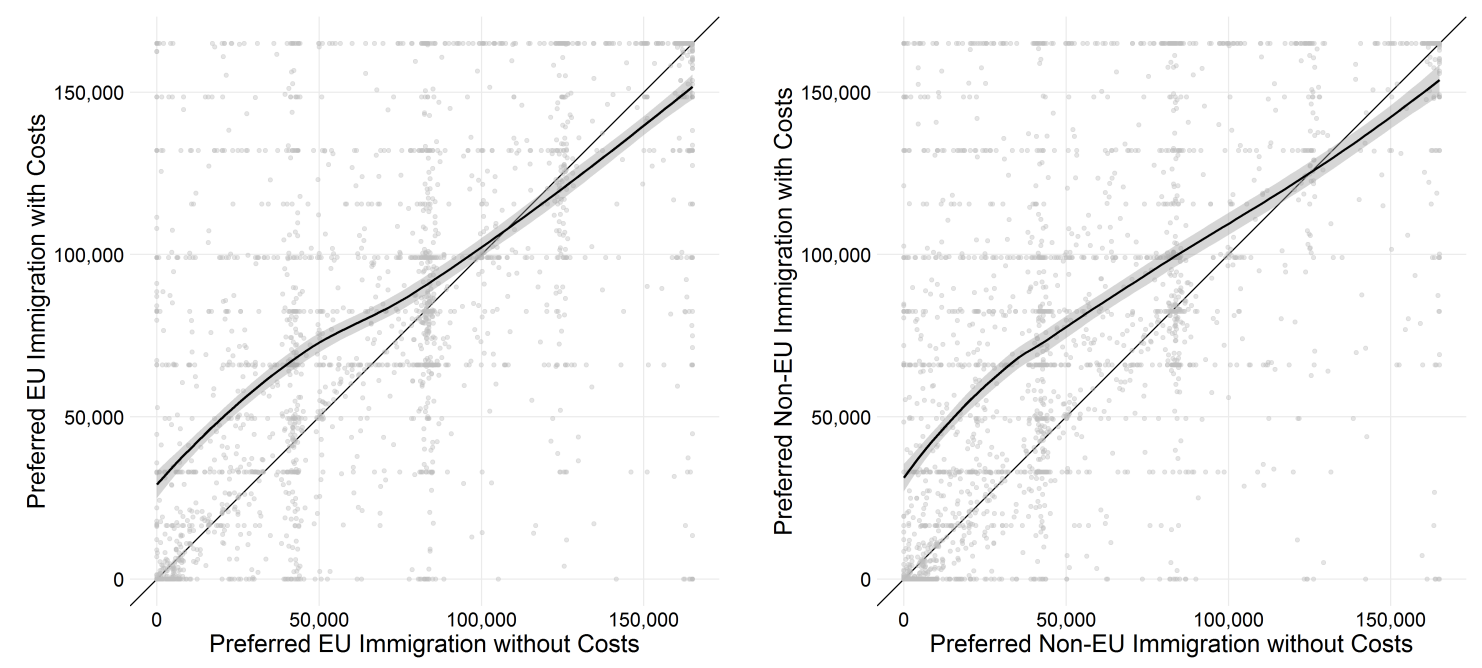

Figure 3: Preferred Constrained and Unconstrained Levels of Immigration, EU and nonEU Separated

erences (y-axis) for total net immigration; the solid black line represents the line $y=x$. The LOESS curve shows how cost constraints shift preferences among those with varying degrees of preferred immigration. Respondents who prefer close to zero net annual migration (lower left area of figure) substantially shift their preferences once costs are imposed, as evidenced by the vertical shift in the curve in the lower half of the preference distribution. ${ }^{8}$ This general pattern also holds separately for EU and non-EU immigration (see Figure 3). Reminding citizens of the reality that reducing immigration comes with economic constraints moves the preferences of the most restrictionist individuals rather than those with preferences for more moderate reductions. These individuals appear willing to compromise their preferred immigration level to limit personal or social economic harm, something not obvious from asking them solely for their unconstrained preferences over immigration numbers.

We further consider how preferences vary along salient personal characteristics: namely those who voted Leave and Remain in the 2016 referendum and those of varying socioeconomic status. Leave voters' unconstrained preferences were for a reduction in total net annual immigration of 249,081 ( $\mathrm{SE}=2313)$ per annum, down to $25 \%$ of current levels. Remain voters were more favorable toward immigration but still favored a large reduction of 134,972 ( $\mathrm{SE}=3128$ ) in the unconstrained context, down to $59 \%$ of current levels. Despite these differences in unconstrained preferences, their price-elasticities appear to be similar. Table 3 provides a summary of treatment effects by referendum vote. Both Leave and Remain voters appear sensitive to costs, with Remain voters particularly sensitive to high personal costs.

\footnotetext{
${ }^{8} \mathrm{~A}$ ceiling dynamic prevents those whose unconstrained preferences match the status quo from expressing preference for even higher net migration once costs are imposed.
} 
Table 3: Treatment Effects, by Referendum Vote

\begin{tabular}{lcc}
\hline \hline & \multicolumn{2}{c}{ Change in Preferred Immigration Levels } \\
\cline { 2 - 3 } & Leave & Remain \\
\hline 5\% Personal Income & $-2,083.2$ & $6,324.7$ \\
& $(6,003.2)$ & $(6,508.0)$ \\
& & \\
$10 \%$ GDP & $4,767.8$ & $4,076.5$ \\
& $(6,551.9)$ & $(6,387.7)$ \\
10\% Personal Income & $4,724.0$ & $22,151.3^{*}$ \\
& $(6,757.3)$ & $(6,888.1)$ \\
Constant & $28,178.6^{*}$ & $24,460.5^{*}$ \\
& $(4,393.8)$ & $(4,113.5)$ \\
\hline Observations & 1,164 & 1,117 \\
Log Likelihood & $-14,731.6$ & $-14,239.3$ \\
Akaike Inf. Crit. & $29,471.3$ & $28,486.6$ \\
\hline \hline Note: & & $* p<0.05$
\end{tabular}


We might also expect individuals in a lower socioeconomic position to be more sensitive to cost considerations; alternatively those on higher incomes might feel the loss of a percentage of higher income more keenly. Results available in the Appendix indicate that all class groups are responsive to cost constraints and the effect sizes are generally quite similar. Notable, however, is that the lower middle class are particularly sensitive to costs - a 10\% income cost triggers an average shift in favor of nearly 50,000 additional immigrants per year. By and large, however, it would appear that working class individuals are not particularly sensitive to costs — if anything, the opposite.

\section{Conclusion}

We sought to quantify the degree to which citizens' preferred immigration levels are sensitive to economic costs. We introduced a novel constrained preference measure that ties preferences for levels of immigration to associated costs of obtaining those levels. While we find that Britons prefer a reduction in immigration, the constrained measure leads restrictionist respondents to accept somewhat higher immigration levels. This suggests that economic concerns may be better theorized as inhibitors rather than drivers of immigration restriction. Yet, economic threat cannot be ruled out. Future research using our method might ask whether choice constraints involving various levels of income inequality or pressure on services alter individuals' preferred migration levels; or, the measurement approach we use might be effectively deployed in the studying cost constraints of other policy issues. We also find that despite the widespread evidence that British citizens oppose EU immigration, unconstrained opposition to EU migration is lower than opposition to non-EU immigration. This hints at the importance of ethnocultural motivations (see also Kaufmann 2018), something that merits further research.

\section{References}

Bansak, Kirk, Jens Hainmueller, and Dominik Hangartner. 2016. "How economic, humanitarian, and religious concerns shape European attitudes toward asylum seekers." Science 354(6309): 217-222.

Boubtane, E, JC Dumont, and C Rault. 2015. Immigration and Economic Growth in the OECD Countries 1986-2006. Technical report CESIFO Working Paper 5392.

Brader, Ted, Nicholas A. Valentino, and Elizabeth Suhay. 2008. "What Triggers Public Opposition to Immigration? Anxiety, Group Cues, and Immigration Threat." American Journal of Political Science 52(4): 959-978.

Clarke, Harold D., Matthew Goodwin, and Paul Whiteley. 2017. Brexit: Why Britain Voted to Leave the European Union. Cambridge University Press.

Davis, L., and S.S. Deole. 2015. "Immigration, Attitudes and the Rise of the Political Right: The Role of Cultural and Economic Concerns over Immigration." : Forthcoming. 
Duffy, B, and T Frere-Smith. 2014. Perception and Reality: Public Attitudes to Immigration. Technical report Ipsos Mori.

Enos, Ryan D. 2014. "Causal effect of intergroup contact on exclusionary attitudes." Proceedings of the National Academy of Sciences 111(10): 3699-3704.

Hainmueller, Jens, and Daniel J. Hopkins. 2014. "The Hidden American Immigration Consensus: A Conjoint Analysis of Attitudes toward Immigrants." American Journal of Political Science: Forthcoming.

Hainmueller, Jens, and Michael J. Hiscox. 2010. "Attitudes toward Highly Skilled and Low-skilled Immigration: Evidence from a Survey Experiment." American Political Science Review 104(1): 61-84.

Hainmueller, Jens, Michael J. Hiscox, and Yotam Margalit. 2015. "Do concerns about labor market competition shape attitudes toward immigration? New evidence." Journal of International Economics 97(1): 193-207.

Hatton, T.J. 2016. "Immigration, public opinion and the recession in Europe." Economic Policy 31(86): 205-246.

Kaufmann, Eric. 2017. "Can Narratives of White Identity Reduce Opposition to Immigration and Support for Hard Brexit? A Survey Experiment." Political Studies: Forthcoming.

Kaufmann, Eric. 2018. "Why culture is more important than skills: understanding British public opinion on immigration." LSE British Politics and Policy Blog.

Kaufmann, Eric, and Matthew J. Goodwin. 2016. "Does Diversity Produce Hostility: a Meta-Analysis." Paper presented at the Elections, Public Opinion, and Parties,.

Kuklinski, James H., Paul J. Quirk, Jennifer Jerit, and Robert F. Rich. 2001. "The Political Environment and Citizen Competence." American Journal of Political Science 45(2): 410-424.

Lacy, Dean. 2001. "A Theory of Nonseparable Preferences in Survey Responses." American Journal of Political Science 45(2): 239-258.

Lubbers, M. 2006. "Objections to asylum seeker centres: Individual and contextual determinants of resistance to small and large centres in the Netherlands." European Sociological Review 22(3): 243-257.

Newman, Benjamin J. 2013. "Acculturating Contexts and Anglo Opposition to Immigration in the United States." American Journal of Political Science 57(2): 374-390.

Sides, John, and Jack Citrin. 2007. "European Opinion About Immigration: The Role of Identities, Interests and Information." British Journal of Political Science 37(03): 477504 .

Wadsworth, Jonathan, Swati Dhingra, Gianmarco Ottaviano, and John Van Reenan. 2016. Brexit and the Impact of Immigration on the UK. Technical report London School of Economics Centre for Economic Performance. 


\section{A Supplemental Tables}

Table A1. Treatment Effects, Alternative Analysis

\begin{tabular}{|c|c|c|c|}
\hline & \multicolumn{3}{|c|}{ Preferred Immigration Levels (Cost-Constrained) } \\
\hline & EU & Non-EU & All \\
\hline Unconstrained & $\begin{array}{c}0.7^{*} \\
(0.03)\end{array}$ & $\begin{array}{c}0.7^{*} \\
(0.03)\end{array}$ & $\begin{array}{c}0.8^{*} \\
(0.03)\end{array}$ \\
\hline $5 \%$ Personal Income & $\begin{array}{c}-1,058.9 \\
(4,428.8)\end{array}$ & $\begin{array}{c}-380.1 \\
(4,290.9)\end{array}$ & $\begin{array}{c}-1,975.0 \\
(8,176.0)\end{array}$ \\
\hline $10 \%$ GDP & $\begin{array}{r}975.7 \\
(4,276.8)\end{array}$ & $\begin{array}{c}-1,790.2 \\
(4,311.4)\end{array}$ & $\begin{array}{c}-28.1 \\
(8,122.4)\end{array}$ \\
\hline $10 \%$ Personal Income & $\begin{array}{c}8,575.7 \\
(4,568.2)\end{array}$ & $\begin{array}{c}7,213.8 \\
(4,411.3)\end{array}$ & $\begin{array}{c}16,823.6^{*} \\
(8,397.2)\end{array}$ \\
\hline Unconstrained $* 5 \%$ Personal Income & $\begin{array}{c}0.003 \\
(0.04)\end{array}$ & $\begin{array}{c}0.004 \\
(0.04)\end{array}$ & $\begin{array}{c}0.01 \\
(0.04)\end{array}$ \\
\hline Unconstrained * 10\% GDP & $\begin{array}{c}-0.01 \\
(0.04)\end{array}$ & $\begin{array}{c}-0.002 \\
(0.05)\end{array}$ & $\begin{array}{c}-0.01 \\
(0.04)\end{array}$ \\
\hline Unconstrained $* 10 \%$ Personal Income & $\begin{array}{c}-0.1 \\
(0.04)\end{array}$ & $\begin{array}{c}-0.1 \\
(0.05)\end{array}$ & $\begin{array}{c}-0.1 \\
(0.04)\end{array}$ \\
\hline Constant & $\begin{array}{c}29,517.7^{*} \\
(2,959.7)\end{array}$ & $\begin{array}{c}35,968.0^{*} \\
(2,928.2)\end{array}$ & $\begin{array}{c}59,179.4^{*} \\
(5,579.1)\end{array}$ \\
\hline Observations & 2,531 & 2,527 & 2,488 \\
\hline Log Likelihood & $-30,496.5$ & $-30,624.8$ & $-31,503.0$ \\
\hline Akaike Inf. Crit. & $61,009.1$ & $61,265.7$ & $63,021.9$ \\
\hline
\end{tabular}


Table A2. Treatment Effects, by Social Grade

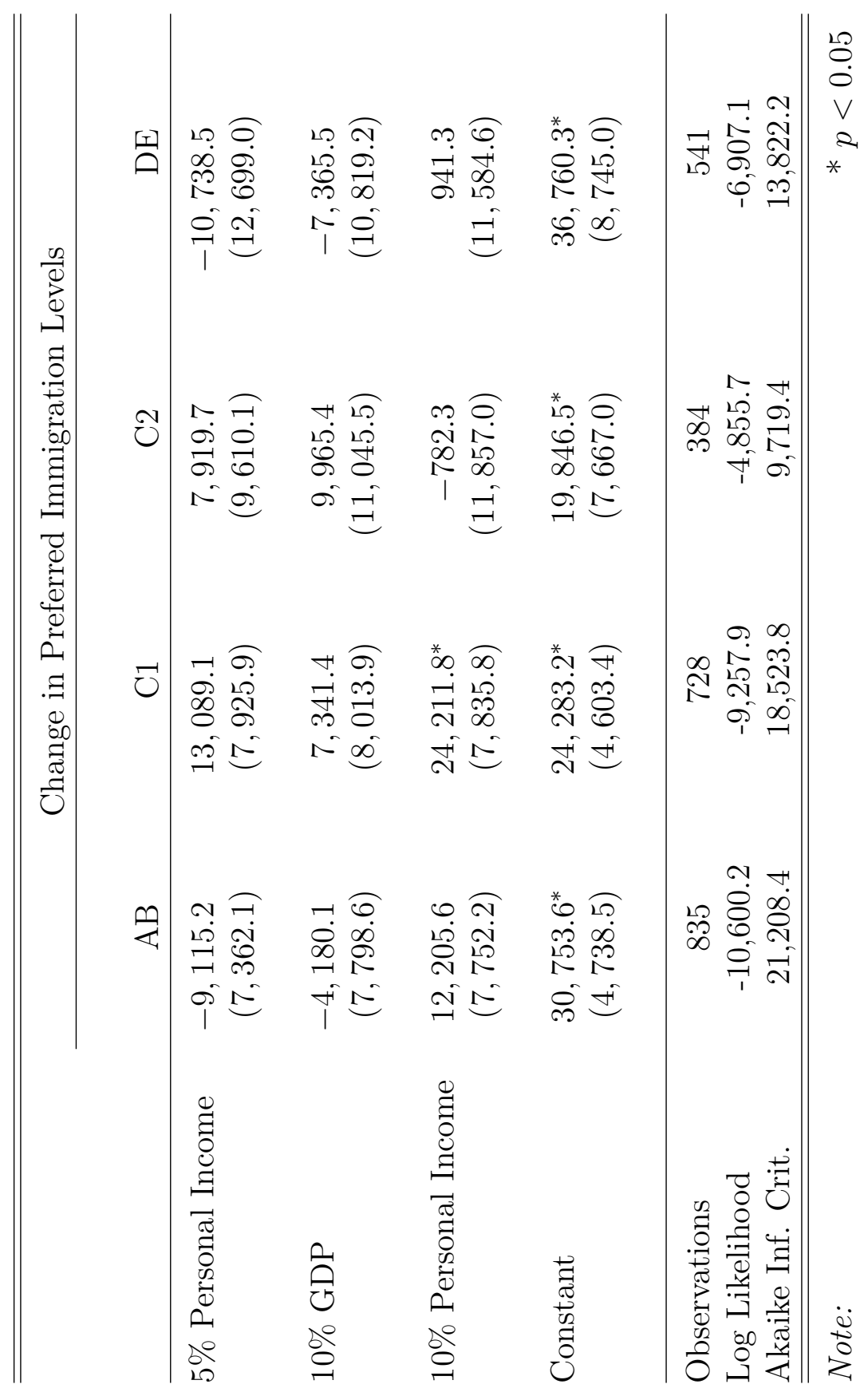


Table A3. Treatment Effects, by 2015 General Election Vote

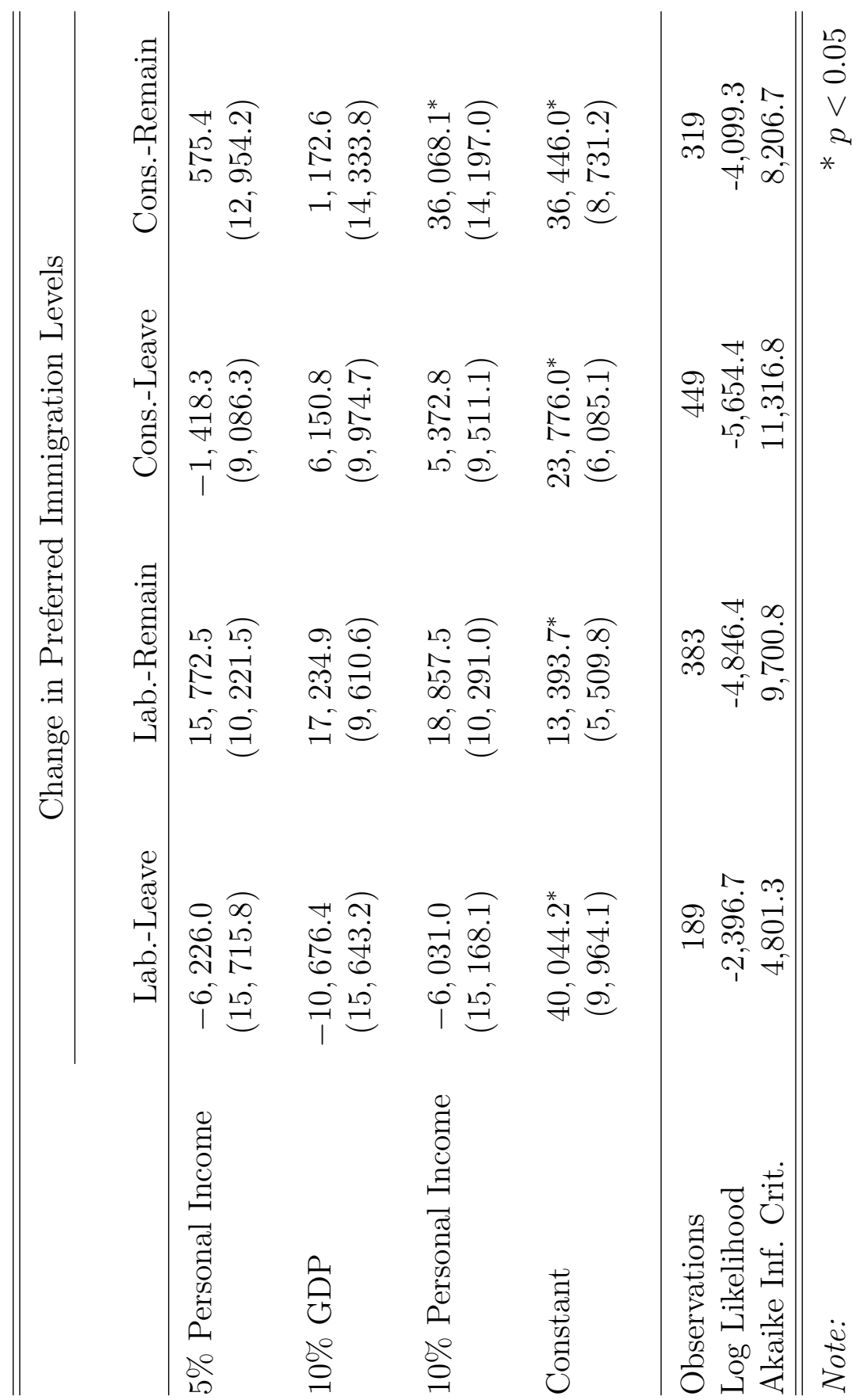


Figure A1. Preferred Constrained and Unconstrained Levels of Immigration, by Referendum Vote

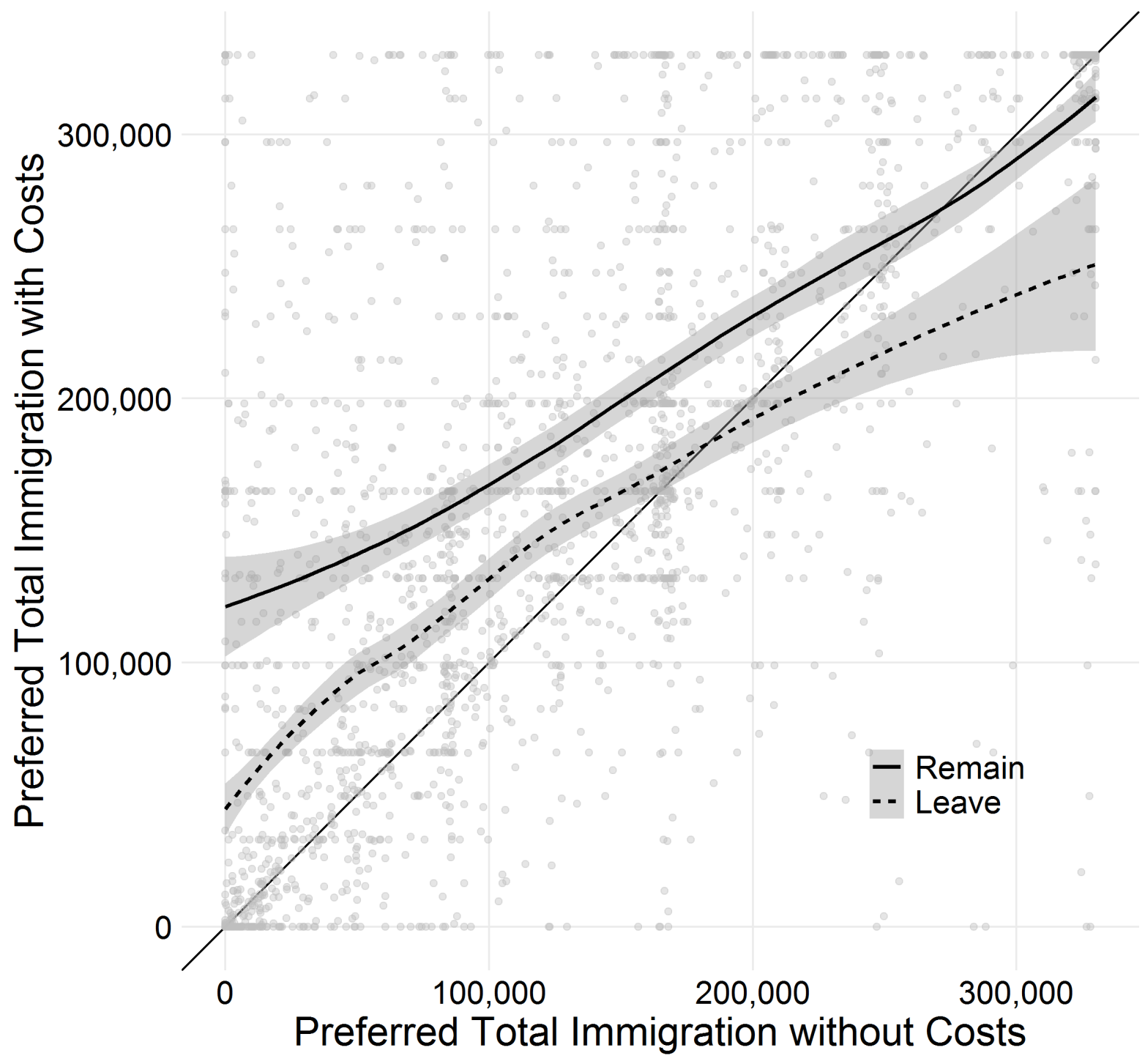




\section{B Screenshots}

Figure 4: Unconstrained Preferences Question Screenshot

\section{YouGov}

According to government statistics, about 3 million European Union citizens and 5 million non-EU citizens live in the United Kingdom. Annually, net migration from the EU is 165,000 and net migration from elsewhere (mainly Asia, Africa and the Middle East) is also 165,000 . This means that 330,000 more people move to the UK each year than leave.

We would like to know how much net migration you would prefer to have from the EU and from elsewhere. Please indicate your preferences as a number: choosing "O" would mean cutting net migration to zero, while choosing "165,000" means keeping levels as they are currently.

How much net migration should there be from the EU?

o net migration

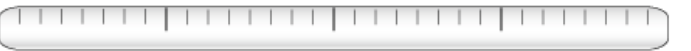

165,000 net migration

$$
\square \text { Not sure }
$$

How much net migration should there be from outside the EU?

o net migration

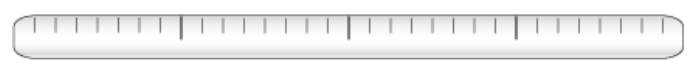

165,000 net migration

$\square$ Not sure 


\section{Figure 5: Constrained Preferences Question Screenshot}

No one knows what will happen, but if reducing EU immigration were to result in a cost to your personal income, how much net migration should there be from the EU?

Imagine that reducing net EU immigration by 165,000 per year will cost $5 \%$ of your personal income. Reducing it by a lower amount will cost less. Given the economic costs you would pay to reduce EU immigration, how much net migration should there be "from the EU"?

As before, please indicate your preference as a number, where "O" would mean cutting net migration to zero and choosing " $165,000^{\prime}$ means keeping levels as they are currently.

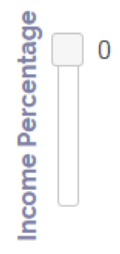

O net migration \& $-5 \%$ effect on your personal income
165,000 net migration \& $0 \%$ effect on your personal income 


\section{Manipulation Check}

Figure 6 provides a simple visual summary of responses to our manipulation check question that asked respondents whether the costs of reducing immigration would be much more costly or much less costly than our stimuli implied.

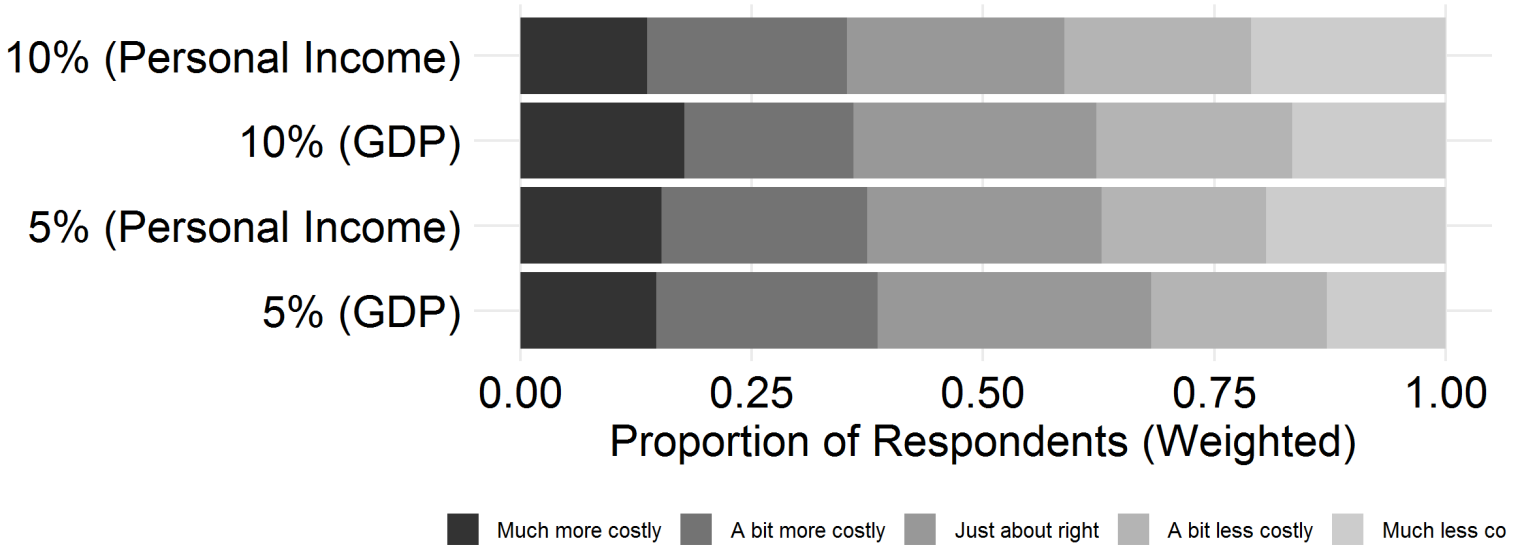

Figure 6: Manipulation Check: Perceived Cost of Reducing Immigration, by Treatment 


\section{Question Wordings}

Full question wordings are as follows:

According to government statistics, about 3 million European Union citizens and 5 million non-EU citizens live in the United Kingdom. Annually, net migration from the EU is 165,000 and net migration from elsewhere (mainly Asia, Africa and the Middle East) is also 165,000 . This means that 330,000 more people move to the UK each year than leave.

We would like to know how much net migration you would prefer to have from the EU and from elsewhere. Please indicate your preferences as a number: choosing " 0 " would mean cutting net migration to zero, while choosing "165,000" means keeping levels as they are currently.

How much net migration should there be from the EU?

Slider scale between 0 and 165,000

How much net migration should there be from outside the EU?

Slider scale between 0 and 165,000

[PAGE BREAK]

No one knows what will happen, but if reducing EU immigration were to result in a cost to [personal income][Gross Domestic Product, a measure of economic well-being], how much net migration should there be from the EU?

Imagine that reducing net EU immigration by 165,000 per year will cost [5\%][10\%] of [personal income][Gross Domestic Product, a measure of economic well-being]. Reducing it by a lower amount will cost less. Given the economic costs you would pay to reduce EU immigration, how much net migration should there be from the EU?

As before, please indicate your preference as a number, where " 0 " would mean cutting net migration to zero and choosing "165,000" means keeping levels as they are currently.

High cost condition:

Slider scale between 0 and 165,000; with additional economic numbers where $0=-10 \%$ and $165,000=-0 \%$

Low cost condition:

Slider scale between 0 and 165,000; with additional economic numbers where $0=-5 \%$ and $165,000=-0 \%$

PAGE BREAK 
[Same question repeated for immigrants from outside the EU] Imagine that reducing net EU immigration by 165,000 per year will cost [5\%][10\%] of [personal income][Gross Domestic Product, a measure of economic well-being]. Reducing it by a lower amount will cost less. Given the economic costs you would pay to reduce EU immigration, how much net migration should there be from outside the EU?

[Same response scales as previous question]

PAGE BREAK

Do you believe the economic costs of reducing immigration that you just read are just about right, or do you think reducing immigration will be much more costly or much less costly?

Much more costly

A bit more costly

Just about right

A bit less costly

Much less costly

Don't know

PAGE BREAK

Reducing EU immigration will affect the percentage of all immigrants that come from Europe as opposed to Asia, Africa, the Middle East, and the rest of the world. [Currently $37 \%$ of all immigrants to the UK are from the EU and the rest are from Asia, Africa, the Middle East, and the rest of the world.] What percentage of all immigrants would to the UK would you like to see coming from the EU?

Slider scale between 0 and 100; 0 labeled 0\% EU and 100\% non-EU; 100 labeled 100\% EU and $0 \%$ non-EU

Control condition: defaults to blank

Treatment condition: defaults to $37 \%$ 